\title{
The Drosophila E74 promoter contains essential sequences downstream from the start site of transcription
}

\author{
Carl S. Thummel \\ Howard Hughes Medical Institute, Department of Human Genetics, University of Utah Medical Center, Salt Lake City, Utah \\ 84132 USA
}

The Drosophila E74 gene is one of a small set of genes induced directly by the steroid hormone ecdysone at the onset of metamorphosis. Both in vitro and in vivo transcription assays have been used to delineate the promoter for the 6-kb E74 mRNA. Sequences upstream from position -83 had little effect on the amount of RNA synthesized in vitro, using extracts prepared from Drosophila Kc tissue culture cells. Deletion of a $5^{\prime}$-flanking TATA consensus sequence had no effect on the accuracy of transcriptional initiation and resulted in an increase in RNA synthesis, suggesting removal of a repressor binding site. Surprisingly, removal of the first two nucleotides of the transcribed region still allowed relatively high levels of transcription from the correct start site position. Removal of five additional nucleotides inactivated the promoter. In vitro transcription of a series of $3^{\prime}$ deletions defined the $3^{\prime}$ in vitro promoter boundary at position +43 . Additional 5 '-flanking sequences, between -181 and -83 , were found to be necessary for efficient transcription in transfected Kc tissue culture cells. Two transcription factors that interact with the E74 promoter, zeste and GAGA, were studied in DNAbinding assays. zeste binds to two sites within the $E 74$ promoter. These sites overlap with three of the six GAGA-binding sites. The zeste- and GAGA-binding sites lie within domains identified by deletion mapping as cis-acting transcriptional control elements.

[Key Words: Drosophila; transcription factor; promoter; ecdysone; gene regulation; zeste; GAGA]

Received January 26, 1989; revised version accepted March 22, 1989.

The steroid hormone ecdysone triggers a cascade of gene expression at the end of larval development in Drosophila, signaling the onset of metamorphosis. The effects of ecdysone on gene expression have been inferred from extensive studies of the puffing patterns of the larval salivary gland polytene chromosomes. Ecdysone directly induces the formation of approximately six early puffs. These puffs appear to encode regulatory proteins that repress their own expression and induce the formation of $>100$ late puffs (Ashburner 1972; Ashburner et al. 1974). The products of the late puffs are thought to be directly responsible for allowing metamorphosis to proceed. A similar network of interacting regulatory genes has been found to play an important role in pattern formation during early Drosophila embryogenesis (Akam 1987; Scott and Carroll 1987).

As a first step toward understanding the molecular basis of this regulatory hierarchy, we have been studying $E 74$, an ecdysone-inducible gene isolated from the 74EF early puff. Genetic analysis of E74 indicates that this gene encodes essential function(s) that are required during late larval and early pupal development (Burtis 1985, and unpubl.). This gene has a remarkably complex structure, reminiscent of the homeotic genes of Drosophila. E74 encodes at least three RNAs from unique start sites. The distal promoter directs the synthesis of a $60-\mathrm{kb}$ primary transcript that is spliced to form a $6-\mathrm{kb}$ mRNA (Burtis 1985; K. Burtis, C. Thummel, C.W. Jones, and D. Hogness, in prep.). The other transcripts, between 4.7 and $5.0 \mathrm{~kb}$ in length, are derived from several start sites that are located $\sim 40 \mathrm{~kb}$ downstream from the 6-kb RNA promoter (F. Karim and C. Thummel, unpubl.). Synthesis of the 6-kb mRNA is directly inducible by ecdysone at the level of transcriptional initiation (C. Thummel, K. Burtis, and D. Hogness, in prep.). The length of the transcribed region imposes a 1-hr delay between the time of hormone addition and the appearance of processed cytoplasmic 6-kb mRNA. This transcriptional delay provides evidence in support of a model that gene length may play an important role in controlling the timing of gene expression during development (Kornfeld et al. 1989; C. Thummel, K. Burtis, and D. Hogness, in prep.).

Precise definition of the promoter for the 6-kb E74 mRNA is a necessary prerequisite for further characterization of its transcriptional regulation. Transcriptionally active extracts have been prepared from embryos (Soeller et al. 1988) and Drosophila tissue culture cells (Parker and Topol 1984). These extracts have been used to delineate the promoters of several Drosophila genes, 
including alcohol dehydrogenase (Heberlein et al. 1985), fushi tarazu (ftz) (Topol et al. 1987), engrailed (en) (Soeller et al. 1988), Antennapedia P2 (Perkins et al. 1988), and Ultrabithorax (Biggin and Tjian 1988). Complementing this approach, promoter activity can be monitored in transfected tissue culture cells by transient expression of a linked marker gene. This approach has been used to study the heat shock (Amin et al. 1985; Pelham 1982), en (Soeller et al. 1988), and actin (BondMathews and Davidson 1988) promoters. Genes introduced into tissue culture cells by transfection appear to be efficiently expressed, even though the endogenous copy may remain quiescent (Benyajati and Dray 1984). This system thus provides a rapid means for identifying the cis-acting sequences needed for transcription in intact cells.

Both in vitro transcription and transient expression assays in transfected tissue culture cells have been used to map the promoter for the 6-kb E74 mRNA. Much of the $5^{\prime}$-flanking DNA is dispensable for efficient transcription in vitro. Surprisingly, the minimal sequences needed to direct RNA synthesis map to a 40-bp region downstream from the start site of transcription. This sequence contains a TATA consensus element. A more conventional, $5^{\prime}$-flanking TATA consensus sequence is dispensable for transcription and has no effect on the fidelity of transcriptional initiation. Additional upstream sequences, between -83 and -181 , are required for efficient expression in transfected tissue culture cells.

The binding sites were determined for two transcription factors that interact with the $E 74$ promoter, zeste, and GAGA. The zeste locus in Drosophila has been studied extensively for its affects on transvection, a phenomenon whereby a gene on one chromosome can interact with its homolog, as long as those genes are brought into close proximity by chromosomal pairing (Kaufman et al. 1973; Gelbart and Wu 1982). The zeste gene has been cloned (Mariani et al. 1985; Gunaratne et al. 1986; Pirrotta et al. 1987) and found to encode a sitespecific DNA-binding protein that activates the $U b x$ promoter in vitro (Biggin et al. 1988). zeste protein also binds to a variety of genes that do not appear to show transvection effects, indicating that it may function as a general transcription factor (Benson and Pirrotta 1988). In vivo expression experiments indicate that zeste activates $E 74$ transcription. Expression from the E74 promoter is induced 90-fold upon cotransfection of Drosophila tissue culture cells with a zeste expression plasmid (M. Goldberg and M. Krasnow, pers. comm.). As shown here, zeste protein binds to two sites in the E74 promoter, within the region required for efficient transcription.

A second transcription factor, GAGA, originally was identified by its interactions with the en (Soeller et al. 1988 ) and $U b x$ (Biggin and Tjian 1988) promoters. The binding site for this protein can overlap zeste-binding sites, suggesting that these factors may interact with each other (Biggin and Tjian 1988; Biggin et al. 1988). Footprinting experiments indicate that the GAGA factor binds to six regions upstream from the start site of $E 74$ transcription. Three of these sites overlap with the zeste-binding sites.

\section{Results}

\section{Deletion mutagenesis of the $\mathrm{E} 74$ promoter}

The $5^{\prime}$ end of the 6-kb E74 mRNA has been mapped using a combination of primer extension and S1 analyses. The same start site is used throughout development and in ecdysone-treated $\mathrm{Kc}$ tissue culture cells (Burtis 1985; K. Burtis, C. Thummel, C.W. Jones and D. Hogness, in prep.). Transcription initiates with a purine and the 5 ' sequence matches the consensus for Droso-

Table 1. Summary of E74 promoter mapping

\begin{tabular}{|c|c|c|c|c|c|}
\hline \multicolumn{3}{|c|}{ In vitro transcription } & \multicolumn{3}{|c|}{ Transient expression assays } \\
\hline $5^{\prime}$ end point & $3^{\prime}$ end point & Average \pm S.D. & $\overline{5^{\prime} \text { end point }}$ & $3^{\prime}$ end point & Average \pm S.D \\
\hline-1200 & +175 & $91 \pm 12$ & -1200 & +175 & $68 \pm 26$ \\
\hline-487 & +175 & $93 \pm 11$ & -840 & +53 & $72 \pm 26$ \\
\hline-305 & +175 & $100 \pm 11$ & -487 & +53 & $78 \pm 26$ \\
\hline-181 & +175 & $96 \pm 12$ & -232 & +53 & $99 \pm 14$ \\
\hline-153 & +175 & $85 \pm 24$ & -181 & +53 & $100 \pm 18$ \\
\hline-83 & +175 & $79 \pm 14$ & -153 & +53 & $70 \pm 18$ \\
\hline-65 & +175 & $64 \pm 9$ & -97 & +53 & $20 \pm 10$ \\
\hline-56 & +175 & $45 \pm 13$ & -83 & +53 & $10 \pm 2$ \\
\hline-44 & +175 & $42 \pm 7$ & -65 & +53 & $9 \pm 4$ \\
\hline-31 & +175 & $25 \pm 8$ & -44 & +53 & $4 \pm 1$ \\
\hline-17 & +175 & $52 \pm 8$ & -17 & +53 & 2 \\
\hline-8 & +175 & $33 \pm 11$ & +3 & +53 & 0 \\
\hline+3 & +175 & $13 \pm 6$ & & & \\
\hline+8 & +175 & 0 & & & \\
\hline+3 & +43 & 0 & & & \\
\hline-487 & +175 & 100 & & & \\
\hline-487 & +61 & 100 & & & \\
\hline-487 & +43 & 100 & & & \\
\hline-487 & +24 & 0 & & & \\
\hline
\end{tabular}

The averages and standard deviations (S.D.) were calculated as described in Methods. 
phila RNAs (Hultmark et al. 1986). The DNA sequence flanking the start site of transcription is depicted in Figure 1. Two Goldberg-Hogness TATA consensus sequences can be identified. These sequences contain a stretch of seven As and Ts flanked by GC-rich regions (Goldberg 1979; Breathnach and Chambon 1981). One TATA consensus lies between nucleotides -17 and -23 , relative to the start site of E74 transcription (position +1 ). The second TATA consensus lies downstream from the start site of transcription, between +34 and +40 .

A set of fourteen $5^{\prime}$ and seven $3^{\prime}$ DNA deletions were made around the start site of $E 74$ transcription, as described in Methods. The deletion end points are shown in Figure 1.

Essential promoter sequences lie downstream from the start site of transcription

Extracts for in vitro transcription were prepared from spinner cultures of Drosophila Kc tissue culture cells. Initially, $0.125,0.25$, and $0.5 \mu \mathrm{g}$ of each $5^{\prime}$ deletion template were used to direct RNA synthesis in vitro. The levels of RNA approximately paralleled the amount of DNA in the reaction, indicating that the template concentration was not in excess. Furthermore, no RNA was synthesized in the presence of $1 \mu \mathrm{g} / \mathrm{ml} \alpha$-amanitin, indi-

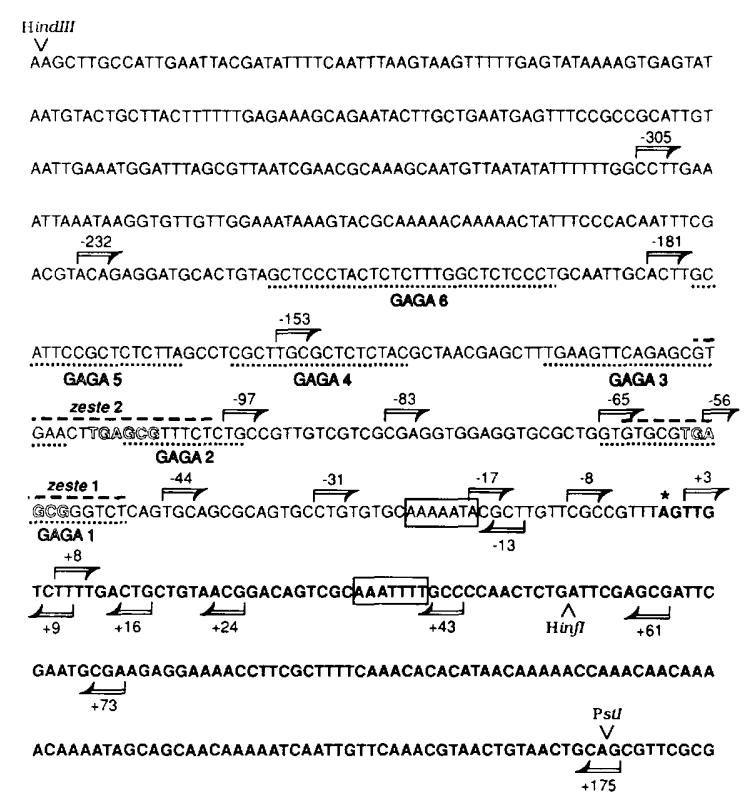

Figure 1. The DNA sequence flanking the start site of transcription for the 6-kb E74 mRNA. The sequence extends from the HindIII site, 487 bp upstream from the start site of transcription $(-487)$ to 240 bp downstream from the start site $(+240)$. Transcription initiates with an A nucleotide, shown by an asterisk $\left({ }^{*}\right)$ at position +1 . The transcribed sequences are in boldface type; and the two TATA consensus sequences are in boxes. The $5^{\prime}$ deletion end points are marked above the sequence, and the $3^{\prime}$ deletion end points are marked below. zeste (dashed line) and GAGA footprints (dotted line), from Fig. 6, are underlined and numbered. The consensus zeste-binding site nucleotides are outlined. cating that transcription was directed by RNA polymerase II (data not shown). Subsequent reactions were performed with $0.5 \mu \mathrm{g}$ of $E 74$ template mixed with 0.25 $\mu \mathrm{g}$ of DNA containing the actin $5 \mathrm{C}$ exon 1-proximal promoter (Fig. 2). The actin transcripts were used as an internal control.

Removal of $5^{\prime}$-flanking DNA from upstream of position -83 had little effect on the levels of RNA synthesized in vitro (Table 1 ; Figs. 2A and 5). Additional deletion of sequences, to position -31 , reduced transcriptional activity threefold. Removal of the 5 '-flanking TATA sequence, with the -17 deletion, unexpectedly resulted in a stimulation of transcription. Further deletion, past the start site of transcription to position +3 , still allowed RNA synthesis at $\sim 13 \%$ of maximal ac-

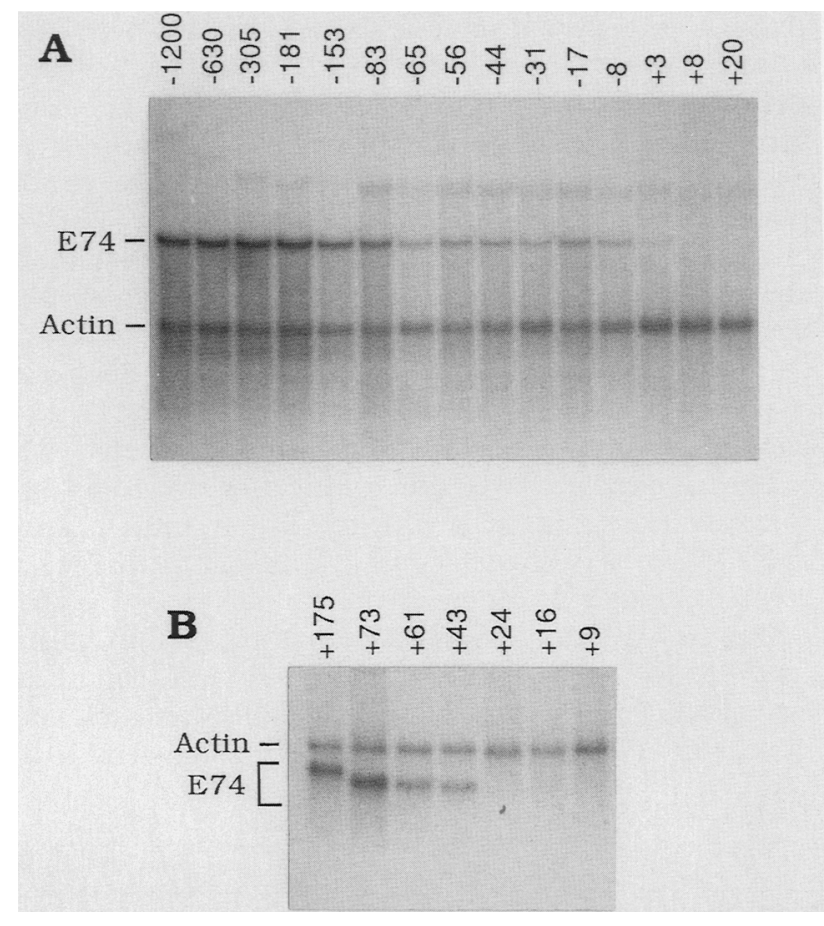

Figure 2. Run-off transcripts synthesized in vitro from the $5^{\prime}$ and $3^{\prime}$ deletion templates. Reactions were performed as described in Methods. (A) The 5' E74 deletions (listed on top) were digested with $S c a I$ to cut within the ampicillin resistance gene of the pUC19 vector. This allowed the synthesis of a transcript 1912 nucleotides in length (E74). Plasmid pDmA2 (Fyrberg et al. 1983) was cut with SalI to generate a 982-nucleotide RNA (actin) from the exon 1-proximal promoter (Bond and Davidson 1986). The light bands at the top are due to a low level of la beling of the template DNA. (B) The $3^{\prime}$ E74 deletions (listed on top) were cut with $S c a$ I to allow the synthesis of transcripts between 1120 and 973 nucleotides in length, depending on the location of the $3^{\prime}$ deletion end point (E74). Plasmid $\mathrm{pDmA} 2$ (Fyrberg et al. 1983) was cut with HindIII to generate a 1371nucleotide RNA (actin) from the exon 1-proximal promoter (Bond and Davidson 1986). In this experiment, the low levels of RNA from the +43 and +61 E74 templates relative to the +73 and +175 templates were due to low levels of template DNA and are not significant. These reactions were repeated four times, and the average results are listed in Table 1 and depicted in Fig. 5. 
tivity. Deletion of an additional 5 nucleotides, however, obliterated in vitro transcriptional activity.

To confirm and extend these observations, transcription of the $5^{\prime}$-deletion templates was assayed by primer extension (Fig. 3). This allowed simultaneous quantitative and qualitative characterization of transcriptional initiation from the $E 74$ promoter. The predominant start site is the same nucleotide as that used in the intact organism, although some start site heterogeneity is seen in vitro that is not present in vivo (Fig. 3; K. Burtis, C. Thummel, C.W. Jones, and D. Hogness, in prep.). As was seen in the run-off transcription assays, removal of 5'flanking DNA between -83 and -31 reduced the efficiency of E74 RNA synthesis. Deletion of the 5'flanking TATA homology (the -17 deletion) did not affect positioning of the start site of transcription. The elimination of functional TATA sequences usually results in a decrease in the fidelity of transcriptional initiation (Grosschedl and Birnstiel 1980; Breathnach and Chambon 1981; Mathis and Chambon 1981; Lebowitz and Ghosh 1982; Osborne et al. 1982). Surprisingly, the +3 deletion template directed RNA synthesis from the correct start site position, even though the wild-type nucleotide had been replaced with vector sequences. Thus, in contrast to most RNA polymerase II promoters, the position of $E 74$ transcriptional initiation is determined by sequences that lie within the transcribed region.

The DNA sequences that lie downstream from the start site of transcription appear to have less influence

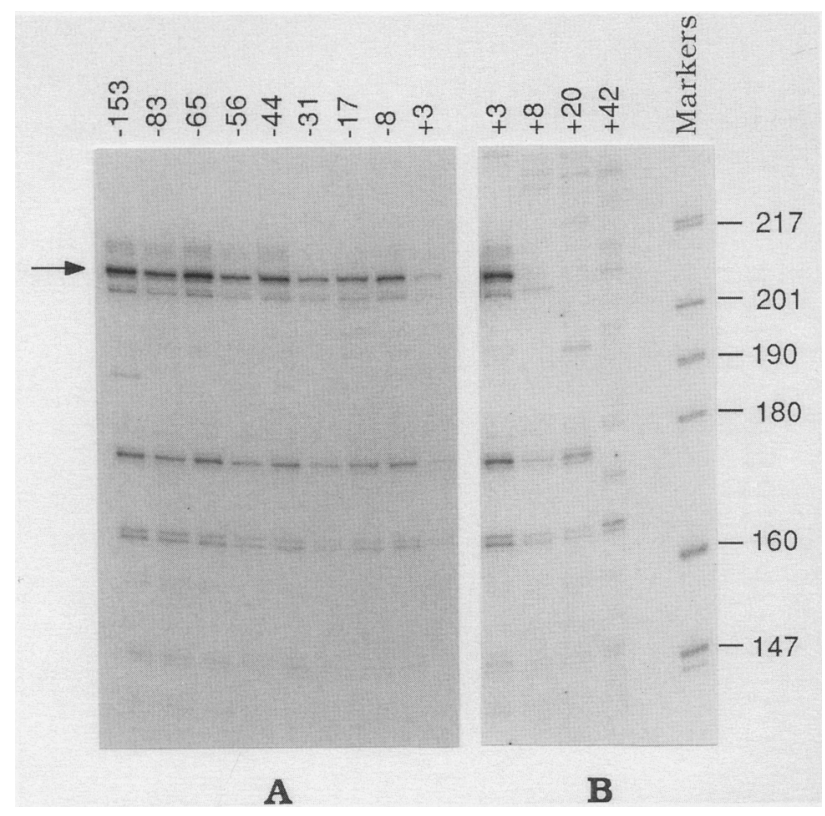

Figure 3. Primer extension analysis of RNA synthesized in vitro from the $5^{\prime} E 74$ promoter deletions. In vitro transcription and primer extension was performed as described in Methods. $\rightarrow$ The 211-nucleotide E74 cDNA. The bands around this extension product represent a low degree of start site heterogeneity seen in vitro. $(A) \mathrm{A} 5.5$-hr autoradiographic exposure of primer extension products from the -153 to $+35^{\prime}$ deletions. $(B)$ The same gel exposed 13 times longer to show the primer extension products from the +3 to $+425^{\prime}$ deletions. on the levels of RNA synthesis directed in vitro/Table 1; Figs. 2B and 5). High levels of RNA were synthesized from $E 74$ templates containing DNA upstream from position +43 . Deletion of 19 additional nucleotides, to position +24 , eliminated transcriptional activity. The minimal region needed for in vitro transcription thus maps between positions +3 and +43 , entirely within the transcribed region of the gene.

To test whether this 40-bp region can function independently as a promoter, this sequence was synthesized and inserted into pUC19 in the same sequence context as the promoter deletions (see Methods). No RNA synthesis could be detected when this construct was used to program in vitro transcription reactions, as assayed by either run-off transcription or primer extension /data not shown). Thus, although the 40-bp internal region is necessary for in vitro RNA synthesis, this sequence is not sufficient to function as an independent promoter.

\section{The E74 promoter requires more distal 5'-flanking sequences in vivo}

Transient expression of a reporter gene in transfected tissue culture cells offers a relatively simple means of measuring promoter activity in vivo. The reporter gene encoding chloramphenicol acetyltransferase (CAT) was chosen for this study because Drosophila cells contain no background CAT enzyme activity and the assay is both rapid and sensitive (Gorman et al. 1982; Thummel et al. 1988). Twelve of the $5^{\prime} E 74$ promoter deletions, with end points extending from -1200 to +3 , were inserted into pC4cat in the correct orientation to direct CAT transcription from the $E 74$ promoter (see Methods). A positive control was also constructed in which the copia promoter was joined to the CAT reporter gene. These DNAs were introduced by calcium phosphate coprecipitation into Kc tissue culture cells - the same cell line that was used to make the in vitro transcription extracts described above. Crude extracts were prepared 2 days after transfection and assayed for CAT enzyme activity (Fig. 4). A summary of this data is listed in Table 1 and shown schematically in Figure 5.

Deletion of $5^{\prime}$-flanking E74 DNA between -1200 and -232 resulted in a slight increase in CAT activity. Additional deletion of DNA between -181 and -83 had a dramatic effect on the activity of the $E 74$ promoter, reducing expression 10-fold. Further removal of sequences between -65 and -44 resulted in a twofold reduction in activity and additional deletion of DNA, between -17 and +3 , eliminated promoter activity. Thus, more distal $5^{\prime}$-flanking DNA is needed for maximal transcription in transfected tissue culture cells than is needed in vitro. Plasmids that had a 3' boundary at the HinfI site at +53 or the PstI site at +175 showed no significant difference in CAT expression (Table 1). The fully active $E 74$ promoter thus maps between -181 and +53 . For comparison, the level of CAT expression directed by the copia promoter was approximately one-third the amount of expression directed by the -1200 E74-cat construct. Attempts were also made to determine whether treat- 
Figure 4. Transient CAT expression directed by $5^{\prime}$ E74 promoter deletions in transfected Kc tissue culture cells. The CAT expression constructs, transfections, and CAT assays are described in Methods. A copia promoter control and 10 of the $125^{\prime}$ deletions tested are shown. Aliquots were removed from the CAT assays at $20|a\rangle, 40(b)$, and $60(c)$ min to generate a time course of CAT activity. The acetylated (upper two spots) and unacetylated (lower spot) forms of chloramphenicol were resolved by thinlayer chromatography and autoradiography overnight without enhancement. The origin, where the sample was spotted, is at the bottom. The cumulative results from these experiments are listed in Table 1 and depicted in Fig. 5.

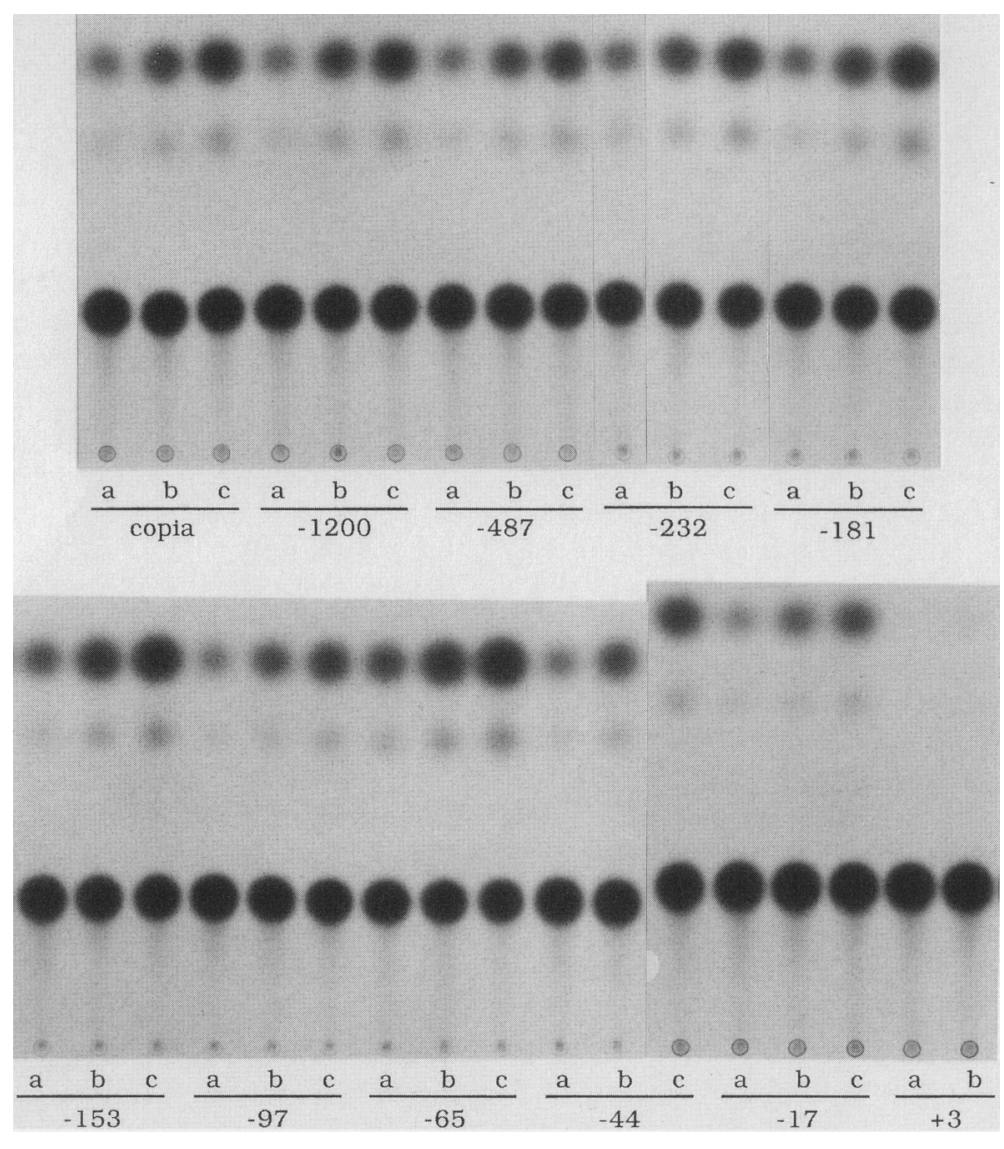

moter deletions, RNA was isolated from one set of transfected plates and reverse transcribed using a CATspecific primer. The lengths of the extension products corresponded to accurate initiation at the $E 74$ start site, and the amounts of cDNA paralleled the levels of CAT enzyme activity (data not shown). This indicated that the enzyme assays were a faithful representation of the
Figure 5. Summary of in vitro and in vivo E74 promoter mapping. The data from Table 1 are presented graphically by plotting the percent of maximum transcriptional activity as a function of the deletion end point on the DNA. (O) Data from the in vitro transcription assays, $(\bullet)$ the E74-cat transient expression data. The first exon of the 6-kb mRNA (Exon 1). TATA consensus sequences (boxes), and footprints (lettered circles) are shown for reference. The doubleheaded arrow marks the minimal sequences needed for transcriptional activity in vitro.

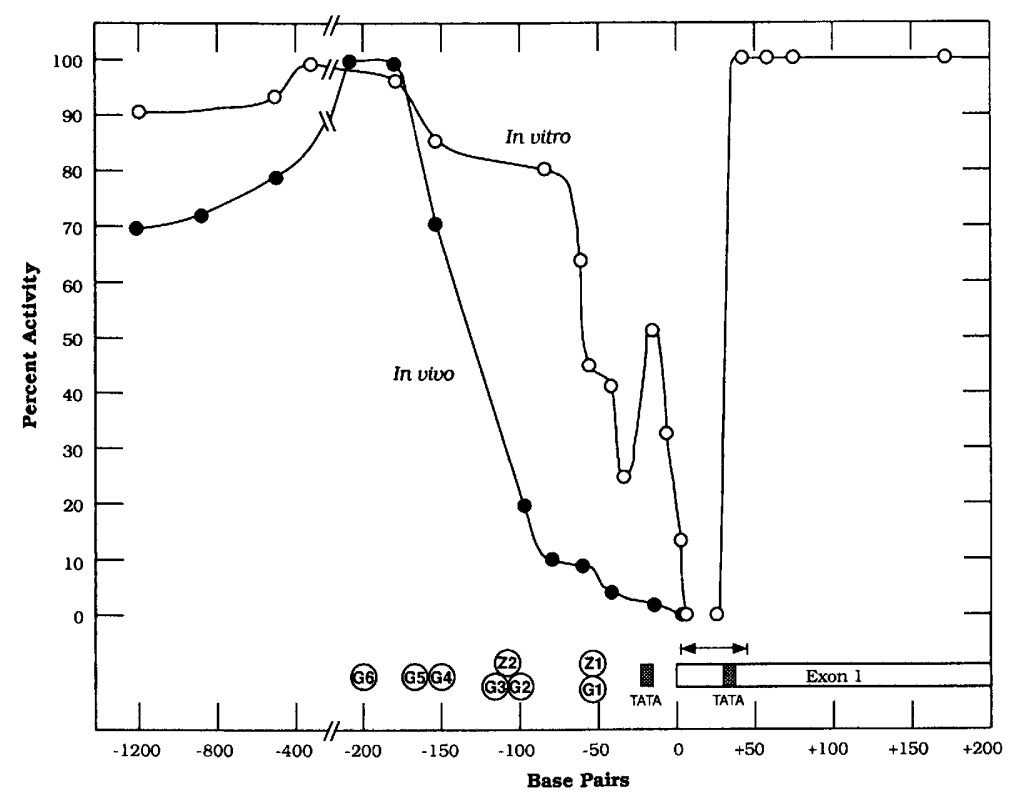


levels of CAT mRNA synthesized by the $E 74$ promoter deletions.

\section{zeste and GAGA transcription factors interact with the} E74 promoter

In vivo expression experiments indicate that zeste activates transcription from the $E 74$ promoter (see Discussion; M. Goldberg and M. Krasnow, pers. comm.). In addition, three consensus sequences for zeste binding $(\mathrm{C} / \mathrm{T}$ $\mathrm{GAGC} / \mathrm{TG}$; Benson and Pirrotta 1988; Biggin et al. 1988) can be found within the DNA flanking the $E 74$ promoter. These sequences are adjacent to several potential GAGA-binding sites, a different transcription factor that may interact with zeste (Biggin and Tjian 1988). zeste and GAGA protein purified from Kc cells (kindly provided by $M$. Biggin and R. Tjian) were used in DNase I protection assays to test whether these transcription factors could indeed bind to the $E 74$ promoter. Two E74 deletions were $5^{\prime}$-labeled on the antisense strand at either nucleotide +175 or -13 and used as probes for DNase I footprinting. This allowed 565 bp of DNA, between -470 and +95 , to be scanned for binding sites.

Two zeste footprints were found within the E74 promoter region (Fig. 6). These footprints each contain a zeste consensus binding sequence $\left[\mathrm{C} / \mathrm{TGAGC} / \mathrm{TG}_{\mathrm{T}}\right.$, see Fig. 1; Benson and Pirrotta 1988; Biggin et al. 1988). Six GAGA footprints were also identified (Fig. 6). Three of these footprints (GAGA 1, 2, and 3) overlap the zestebinding sites (Fig. 1). No footprints were detected between -216 and -470 bp (Fig. 6) or between -47 and +95 (data not shown). The zeste and GAGA footprints lie within sequences that are important for in vitro and in vivo $E 74$ transcriptional activity (Fig. 5).

\section{Discussion}

In vitro transcription of a series of $5^{\prime}$ and $3^{\prime}$ DNA deletions has defined the minimal sequences needed for transcriptional activity from the ecdysone-inducible E74 promoter. Relatively high levels of transcription were obtained with DNA containing sequences downstream from position -83 , relative to the start site of transcription. Deletion of $5^{\prime}$ sequences between -83 and -31 reduced transcription over threefold, suggesting that this region contains sequences needed for transcriptional activation. Deletion of an additional $14 \mathrm{bp}$, between -31 and -17 , resulted in a reproducible twofold increase in transcription. This effect is consistent with the possibility that this region contains a binding site for a transcriptional repressor. The Antennapedia P2 promoter contains a similar element which, when deleted, results in a stimulation of transcription (Perkins et al. 1988). There is no apparent sequence similarity between the 15-bp putative repressor binding site in the Antennapedia P2 promoter and this 14-bp region in E74. Further deletion of $E 74$ DNA, between -17 and +8 , results in a gradual decrease and, ultimately, elimination of transcriptional activity.

Many eukaryotic genes contain a 7-bp TATA con-

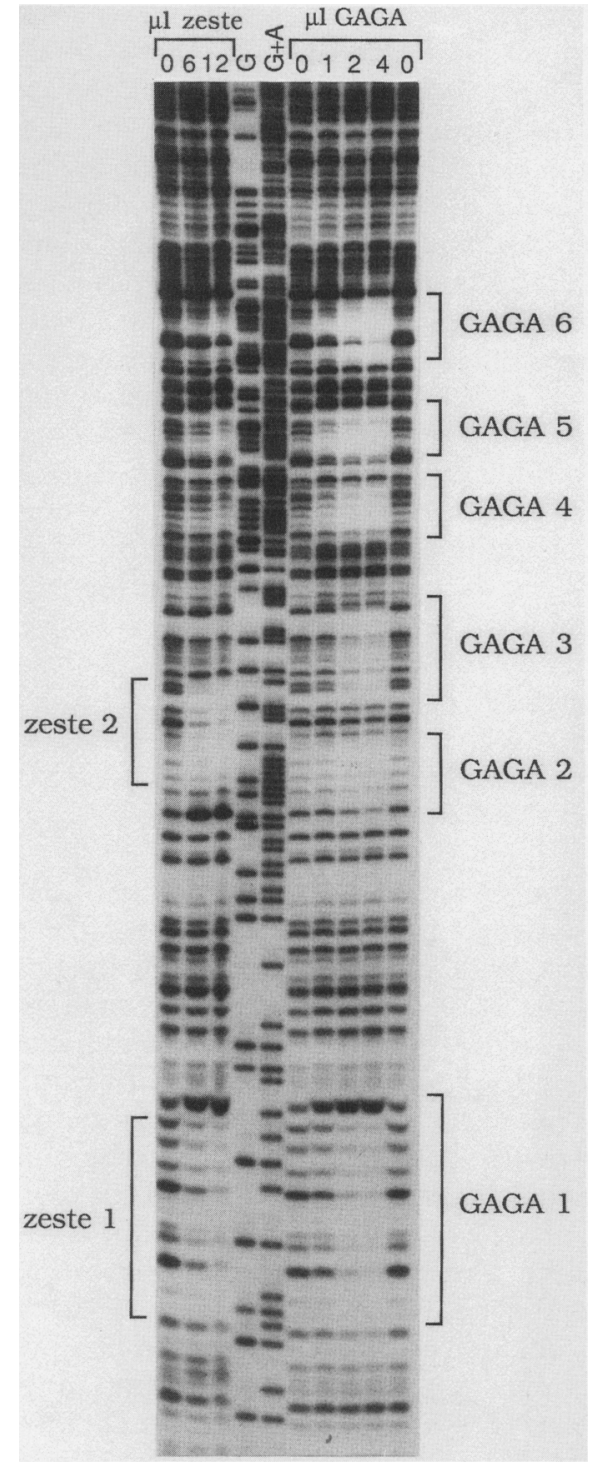

Figure 6. Footprint analysis of zeste and GAGA-binding sites. DNase I protection assays were performed as described in Methods. The DNA probe was 5 -end-labeled on the antisense strand at nucleotide - 13. Maxam and Gilbert (1980) G and $\mathrm{G}+\mathrm{A}$ reactions were used as markers. (Top) The amounts of protein used for binding. The footprint boundaries with their number designations are shown on the sides. The positions of these footprints in the E74 DNA sequence are shown in Fig. 1. No footprints were detected between -47 and +95 , using the DNA probe labeled at +175 (data not shown).

sensus sequence upstream from the start site of transcription /Goldberg 1979; Breathnach and Chambon 1981). This sequence is the binding site for a transcription factor, Drosophila B factor (Parker and Topol 1984), or mammalian TFIID (Nakajima et al. 1988). Deletion of the TATA element results in an overall decrease in transcriptional activity, as well as an increase in start site heterogeneity, suggesting that the function of this sequence is to correctly position the start site of transcription /Grosschedl and Birnstiel 1980; Benoist and 
Chambon 1981; Breathnach and Chambon 1981; Mathis and Chambon 1981, Lebowitz and Ghosh 1982; Osborne et al. 1982). According to this definition, the 5 '-flanking E74 TATA sequence, located between -17 and -23 , is nonfunctional. It lies within a 14-bp region which, when deleted, results in transcriptional activation - the opposite effect expected for deletion of a functional TATA element. In addition, removal of this TATA sequence has no effect on positioning the start site of transcription (Fig. 3). A second TATA consensus sequence, located between +34 and +40 , is a better candidate for being a functional B-factor-binding site. Deletion of this sequence completely inactivates transcription. Furthermore, as discussed below, this TATA sequence lies within the minimal region needed to direct $E 74$ transcription from the correct start site position. Many regulatory proteins can affect transcription by binding to sites either downstream or upstream from the start site of transcription. Proof that this sequence is, in fact, a functional TATA element could be obtained by site-directed mutagenesis, as well as characterizing the interaction of this sequence with purified Drosophila B factor.

Not only is this putative TATA element located in an unusual position in the $E 74$ promoter, but the entire essential promoter region is shifted in a $3^{\prime}$ direction. Deletion analysis of RNA polymerase II promoters usually defines essential sequences that lie within a short region $(\sim 50 \mathrm{bp})$ centered upstream from the cap site (Corden et al. 1980; Hu and Manley 1981; Mathis and Chambon 1981; Lebowitz and Ghosh 1982; Heberlein et al. 1985). Contrary to these examples, deletion of the first two nucleotides of the $E 74$ transcribed region still allows $~ 13 \%$ of maximum transcriptional activity, from the correct start site position (Figs. 2 and 3; Table 1). Transcription from this deletion template initiates from a pyrimidine (T) even though an A, the wild-type initiating nucleotide, is located 1 nucleotide upstream. The sequences that position the start site of transcription must therefore be located downstream from position +3 . Furthermore, the $3^{\prime}$ in vitro promoter boundary maps between +24 and +43 , defining a 40 -bp minimal promoter region, entirely within the transcribed region of the gene. Attempts to detect transcription from a 40-bp oligonucleotide containing this sequence were unsuccessful, indicating that these sequences alone are necessary but not sufficient for transcriptional activity (data not shown). This, most likely, reflects the need for transcriptional activators that can bind to sequences located either upstream or downstream from the minimal promoter region.

The promoters of four other Drosophila regulatory genes have been mapped in vitro: Antennapedia P2 (Perkins et al. 1988), en (Soeller et al. 1988), ftz (Topol et al. 1987), and $U b x$ (Biggin and Tiian 1988). Of these, the en and Antennapedia $\mathrm{P} 2$ promoters behave like the E74 promoter; i.e., removal of all $5^{\prime}$-flanking DNA, including the start site of transcription, does not inactivate the promoter. The $U b x$ promoter also shows an unusually limited dependence on $5^{\prime}$-flanking DNA, as transcrip- tion can still be detected with a deletion template that is missing sequences upstream from position -4 (Biggin and Tjian 1988|. Although other eukaryotic promoters show a requirement for sequences downstream from the start site, no other RNA polymerase II promoters have been found to function in the absence of all $5^{\prime}$-flanking DNA. Whether this positioning of essential promoter sequences within the transcribed region is indeed a phenomenon unique to developmental regulatory genes in Drosophila remains to be determined.

The 5'-flanking sequences needed for $E 74$ transcription in vivo have been mapped by transient expression of E74-cat fusions in transfected Kc tissue culture cells (Fig. 4). The results of this analysis are different from those seen in vitro (Fig. 5). DNA between -181 and -83 is necessary for high levels of transcription in vivo but is dispensable for high levels of transcription in vitro. This disparity is characteristic of enhancer elements that function orders of magnitude more efficiently in intact cells than they do in in vitro reactions (Benoist and Chambon 1981; Sassone-Corsi et al. 1984; Sergeant et al. 1984; Hatzopoulos et al. 1988). Further studies are necessary to determine whether this 100-bp upstream region in $E 74$ can function as a transcriptional enhancer.

There are also some similarities between the in vivo and in vitro promoter mapping data. CAT expression can be detected in cells transfected with the -17 deletion, indicating that sequences near the start site are sufficient for minimal transcriptional activity. This also confirms that transcription can proceed in the absence of the $5^{\prime}$-flanking TATA consensus sequence in vivo. The $3^{\prime}$ boundary for in vivo promoter activity must lie upstream from +53 , as E74-cat fusions with a $3^{\prime}$ boundary at either the HinfI site $(+53)$ or PstI site $(+175)$ direct equal levels of CAT expression (Table 1).

The observation that sequences between -181 and +53 are required for high levels of transcription in tissue culture cells provides important information for constructing $\mathrm{P}$ elements for germ-line transformation studies. Three E74-cat fusions, containing E74 DNA between either $-1200,-580$, or -305 , and position +53 , were used to transform flies. None of these constructs displayed appropriate ecdysone-responsive CAT expression; however, they did show high levels of CAT activity in late embryos, late pupae, and adult flies. These are the times during development when the E74 6-kb mRNA is transcribed in an apparently hormone-independent manner (Burtis 1985; C. Thummel, K. Burtis, and D. Hogness, in prep.). The sequences responsible for this expression, therefore, appear to lie between -305 and +53 (Thummel et al. 1988). Further P-element mapping studies have indicated that the ecdysone-responsive sequences are not within $7.3 \mathrm{~kb}$ upstream from the $E 74$ promoter nor within the downstream sequences, excluding the $15-\mathrm{kb}$ first intron (C. Thummel, unpubl.). Experiments are currently under way to map the ecdysone-responsive sequences in the $E 74$ gene.

zeste protein protects two sites in the $E 74$ promoter against DNase I digestion (Figs. 1 and 6). These interactions agree with the sequence requirements for zeste 
binding described by Benson and Pirrotta (1988). A consensus zeste-binding sequence $(\mathrm{C} / \mathrm{TGAGC} / \mathrm{TG})$ is centered within each zeste footprint (Fig. 1). Furthermore, zeste site 1 is a weaker binding site than zeste site 2 . This can be accounted for by the presence of flanking Gs and Cs adjacent to site 1 , whereas site 2 is flanked by As and Ts, leading to a stronger binding site (Benson and Pirrotta 1988). There is one more consensus zeste-binding sequence within the $565 \mathrm{bp}$ that was scanned for footprints. This sequence, between +56 and +61 , is far enough from sites 1 and 2 that it would function as an independent binding site. Single consensus sequences are usually not bound by zeste protein (Benson and Pirrotta 1988). Furthermore, the two Cs present within this sequence are often correlated with sites that do not bind zeste protein (Benson and Pirrotta 1988). This sequence also appears to be nonfunctional in the transcription assays, as its removal has no effect on either in vitro or in vivo promoter function (Table 1).

The zeste footprint 1 covers a 14-bp sequence, CGTGAGCGGGTCTC, $13 \mathrm{bp}$ of which are shared in common with the distal promoter of the $E 75$ early ecdysone-responsive gene (B. Segraves and D. Hogness, unpubl.). A similar sequence, containing 11 out of the 14 bp, lies within the E74 zeste footprint 2. An overlapping 14-bp identity lies between the start sites for the 4.7- and 5.0-kb E74 RNAs: GTGTGCGTGAGCGG (F. Karim and $C$. Thummel, unpubl.). The significance of these sequence similarities remains unclear, although it is consistent with the possibility that zeste may regulate these other promoters.

The - 65 E74-cat plasmid displays a 90-fold induction of CAT activity when cotransfected with a zesteexpressing plasmid (M. Goldberg and $M$. Krasnow, pers. comm.). zeste-binding site 1 , contained within this construct, therefore appears to be sufficient to mediate zeste activation of $E 74$ transcription. In agreement with this, deletion of footprint 1 reduces in vivo $E 74$ expression over twofold and also reduces in vitro transcriptional activity (Table 1; Fig. 5).

GAGA protein protects six sites against DNase I digestion (Figs. 1 and 6). Two of these sites, 1 and 3 , were not bound with low concentrations of GAGA protein (Fig. 6). These binding sites contain a GAG rather than the stronger binding GAGA or GAGAG motifs found in binding sites 2, 4, 5, and 6 (Biggin and Tijian 1988). GAGA-binding site 1 overlaps almost perfectly with zeste site 1, whereas zeste site 2 covers part of GAGA site 3 and most of GAGA site 2 (Fig. 6). Similar overlaps between zeste and GAGA-binding sites have been seen in the $U b x$ promoter and may indicate functional interactions between these proteins (Biggin and Tjian 1988). There are no GAGA-binding sites between -47 and +95 (data not shown), a region devoid of GAGA consensus binding sequences.

The zeste and GAGA footprints lie within sequences needed for high levels of $E 74$ promoter activity (Fig. 5). In particular, the zeste-binding sites and GAGA sites $2-5$ lie within regions required for high levels of transcription in vivo. Deletion of zeste site 2 and GAGA sites 2-4 results in over a threefold decrease in in vivo promoter activity (Table 1; Fig. 5). Deletion of zeste site 1 and GAGA site 1 generates another twofold decrease in transcription. Deletion of these sites also results in a reduction of promoter activity in vitro (Table 1). No footprints were detected within the $254 \mathrm{bp}$ upstream from GAGA site 6 , a region that has little effect on the levels of E74 transcription either in vitro or in vivo. These results are consistent with the hypothesis that both GAGA and zeste activate transcription from the E74 promoter.

\section{Methods \\ Construction of $\mathrm{E} 74$ promoter deletions}

A 1375-bp PstI fragment of Drosophila DNA, extending from -1200 to +175 relative to the start site of $E 74$ transcription, was inserted into the PstI site of pUC19 (Yanisch-Perron et al. 1985 ) to create pUC4020(-). This plasmid was used to make a series of 5 ' DNA deletions around the start site of transcription. A HindIII-PstI fragment, extending from -487 to +175 relative to the start site of transcription, was inserted into pUC19 (Yanish-Perron et al. 1985) and used to create a series of 3' DNA deletions. This plasmid was designated pUC4019|+1. The initial set of deletions were made by random DNase I digestion in the presence of $\mathrm{Mn}^{2+}$ ions to generate double-stranded cuts (J. Nathans, pers. comm.). The DNase I was titered down to give approximately one cut for every two molecules. The buffer consisted of $20 \mathrm{mM}$ Tris- $\mathrm{HCl}(\mathrm{pH} 7.4), 2 \mathrm{mM} \mathrm{MnSO}_{4}$, and 100 $\mu \mathrm{g} / \mathrm{ml} \mathrm{BSA}$, and reactions were performed at $23^{\circ} \mathrm{C}$ for $20 \mathrm{~min}$. The full-length linear molecules were gel-purified and cut with BamHI to remove DNA between the deletion end point and the $B a m H I$ site. The ends were then repaired with Klenow large fragment DNA polymerase $I$, and the molecules were circularized by ligation at low concentration. This DNA was used to transform E. coli DH1. Molecules that were cut by DNase I within the pUC sequences should only rarely be propagated, because most of these sequences are essential for plasmid viability. Individual clones should therefore be limited to various deletions within the $E 74$ insert DNA. The insert sizes were determined following digestion with HindIII and EcoRI, and selected clones were grown for plasmid preparations.

Additional deletions near the start site of transcription were generated by Bal31 exonuclease digestion (Maniatis et al. 1982) pUC4020 - I DNA was cut with NruI, which cuts once at position -83 . This DNA was then treated with a sufficient amount of $\mathrm{Bal31}$ at $20^{\circ} \mathrm{C}$ for $10 \mathrm{~min}$ to degrade $\sim 50 \mathrm{bp}$ from each end. These molecules were digested with $B a m H I$, the ends were filled in with Klenow DNA polymerase, and the plasmids were recircularized by ligation at low concentration and used to transform $E$. coli $\mathrm{DH} 1$. The clones were screened for inserts of desired size. Recircularization of the original pUC4020(-) DNA cut with NruI and BamHI (filled in) was used to obtain the $-835^{\prime}$ deletion.

The locations of the $5^{\prime}$ and $3^{\prime}$ deletion end points were determined by DNA sequencing of double-stranded plasmid DNA. One microgram of each DNA was annealed to $10 \mathrm{ng}$ of $\mathrm{ml} 3$ sequencing primer (New England Biolabs). The DNAs were then subjected to standard dideoxynucleotide DNA sequencing (Sanger et al. 1977) and resolved on 10\% sequencing gels. One $5^{\prime}$ deletion, at position -630 , was positioned by restriction mapping, as its deletion end point fell outside of the known $E 74$ DNA sequence. 
The 5' DNA deletion clones have end points at the following positions: -1200 (PstI), $-630,-305,-181,-153,-83,-65$, $-56,-44,-31,-17,-8,+3,+8$, and +20 . The $3^{\prime}$ boundary of these DNAs is at position +175 (PstI). The $3^{\prime}$ DNA deletion clones have end points at the following positions: $-13,+9$, $+16,+24,+43,+61,+73$, and +175 (PstI). The 5 ' boundary of these DNAs is at position -487 (HindIII).

To test whether the 40 bp between +3 and +43 could function as an in vitro promoter, two oligonucleotides were synthesized. When annealed, the resultant fragment contained a BamHI site at the $5^{\prime}$ end, as in the $+35^{\prime}$ deletion, and a PstI site at the $3^{\prime}$ end, as in the $+433^{\prime}$ deletion, with the 40 -bp promoter sequence in between. This was inserted between the BamHI and PstI sites in pUC19, to maintain the same sequence context as the $5^{\prime}$ and $3^{\prime}$ DNA deletions. DNA sequencing confirmed that the correct nucleotide sequence was present.

Twelve different E74-cat fusions were created in the vector pC4cat (Thummel et al. 1988). Five different restriction fragments encompassing the $E 74$ promoter were used: a 1375-bp PstI fragment (-1200 to +175$)$, a 900-bp HinfI fragment (-840 to +53 ), a HindIII-Hinfl fragment $(-487$ to +53$)$, a RsaI-HinfI fragment $(-232$ to +53$)$, and a NruI-HinfI fragment $(-83$ to +53 ). The PstI fragment was inserted into the PstI site of pC4cat. The other fragments were blunted with Klenow DNA polymerase and then inserted into the SmaI site of pC4cat. Similarly, seven of the $5^{\prime}$ deletion constructs were digested with $S m a I$ and Hinfl, the ends were filled in with Klenow DNA polymerase, and the $E 74$ promoter fragments were inserted into the Smal site of pC4cat. This created plasmids with $5^{\prime}$ end points at $-181,-153,-97,-65,-44,-17$, and +3 and a common $3^{\prime}$ deletion end point at +53 . In each case, the promoter fragment was inserted in the correct orientation to allow CAT transcription.

\section{In vitro transcription}

Six to eight liters of $\mathrm{Kc}$ tissue culture cells were grown in spinner culture and used to prepare nuclear extracts following the protocol of Parker and Topol (1984). An exception was the last ammonium sulfate precipitation when $0.3 \mathrm{~g} / \mathrm{ml}$ was added slowly to the extract with stirring. In addition, the cytoplasmic fraction was centrifuged at $40,000 \mathrm{rpm}$ for $1 \mathrm{hr}$ and $0.33 \mathrm{~g} / \mathrm{ml}$ ammonium sulfate was added to the supernatant from that centrifugation. This cytoplasmic extract was then processed in parallel with the nuclear extract - the ammonium sulfate precipitate was pelleted, resuspended in buffer $C$, and dialyzed as described by Parker and Topol (1984). The nuclear and cytoplasmic extracts contained from 10 to $30 \mathrm{mg} / \mathrm{ml}$ protein. Runoff transcription reactions were set up essentially as described (Parker and Topol 1984). The Drosophila actin 5C promoter, from pDmA2 (Fyrberg et al. 1983), was used as an internal control. Reactions containing $0.5 \mu \mathrm{g}$ of E74 template, linearized with $S c a I$, and $0.25 \mu \mathrm{g}$ of actin template, cut with either HindIII or SalI, were performed in $50 \mu$ l volumes using $15 \mu 1$ of nuclear extract and $5 \mu \mathrm{l}$ of cytoplasmic extract. Addition of cytoplasmic extract reproducibly stimulated transcription approximately threefold. This is probably due to the presence of factors that leak out of the nucleus during cell lysis. When provided with appropriate transcription factors, cytoplasmic extracts alone can be used to direct RNA synthesis (Biggin and Tiian 1988). The run-off transcripts were resolved by glyoxal agarose gel electrophoresis (McMaster and Carmichael 1977) and autoradiography. The levels of E74 and actin RNAs were determined by densitometer scanning of autoradiograms, such as those shown in Figure 2. The amounts of actin RNA were used to correct the levels of $E 74$ RNA from one reac- tion to another. Transcription of the $5^{\prime}$ deletion templates was performed four times, except for the -487 and -153 deletions, which were repeated three times. The $3^{\prime}$ deletion series /those with a $5^{\prime}$ end point at -487 ) were used in three separate transcription reactions. The averages and standard deviations are listed in Table 1.

For primer extension analysis, E74 RNA was synthesized in vitro in the absence of radioactive nucleotides. Because the $E 74$ deletions were inserted into pUC19, the reverse sequencing primer (New England Biolabs) was used to prime cDNA synthesis. The primer was end-labeled with polynucleotide kinase and annealed to the RNA at $37^{\circ} \mathrm{C}$ for $2 \mathrm{hr}$. Reverse transcription was done as described (Maniatis et al. 1982). This led to the synthesis of a 211-nucleotide cDNA, from the primer binding site to the start site of E74 transcription. The extension products were fractionated on $5 \%$ sequencing gels and visualized by autoradiography.

\section{Tissue culture cell transfection and transient expression assays}

Kc tissue culture cells were plated at a density of $2.5 \times 10^{7}$ cells on 100-mm-diameter tissue culture plates. The following day, $40 \mu \mathrm{g}$ of DNA was added to each plate as a calcium phosphate coprecipitate (DiNocera and Dawid 1983). Chloroquine was added at the same time to a final concentration of $100 \mu \mathrm{M}$. After $5 \mathrm{hr}$, the medium was removed, and the cells were washed once with $1 \times$ HeBS (DiNocera and Dawid 1983) and overlaid with fresh medium. This chloroquine treatment boosted the transfection efficiency of the Kc cells approximately fivefold (Luthman and Magnusson 1983; C. Thummel, unpubl.). The cells were incubated at $25^{\circ} \mathrm{C}$ for $48 \mathrm{hr}$ and harvested. Crude extracts were prepared and CAT assays were done essentially as described (Thummel et al. 1988). From 20 to $500 \mu \mathrm{g}$ of protein was used in the assays, depending on the level of CAT activity. The reactions were scaled up threefold and allowed to proceed at $37^{\circ} \mathrm{C}$ for $1 \mathrm{hr}$. Aliquots were removed after 20,40 , and $60 \mathrm{~min}$ and the reaction was stopped by extracting with ethyl acetate. The acetylated and nonacetylated forms of chloramphenicol were fractionated by thin-layer chromatography and visualized by autoradiography. The spots were cut out and the radioactivity was quantitated by scintillation counting. Linear regression analysis of the percent acetylation as a function of time yielded a straight line, and the slope was used to determine the CAT activity directed by a particular $E 74$ promoter deletion. Bradford assays (Read and Northcote 1981) were then used to quantitate the total protein concentration in each crude extract and calculate the specific CAT activity, for comparison of different templates within an experiment. Four separate transfections and CAT assays were performed. The three values that were most similar were averaged and the standard deviation was calculated, as listed in Table 1. CAT transient expression was variable from one transfection to another, as has been found in mammalian cell culture experiments (C. Gorman, pers. comm.). Nevertheless, the relative values within a transfection series were reproducible.

\section{DNase I protection of zeste and GAGA-binding sites}

Purified zeste and GAGA protein isolated from $\mathrm{Kc}$ cells were a generous gift from M. Biggin and R. Tjian. These proteins had been purified to apparent homogeneity, as determined by silver staining SDS-polyacrylamide gels (M. Biggin, pers. comm.). Two different DNA probes were labeled on the antisense strand and used for footprint analysis. A fragment from +175 to -1200 was 5 '-end-labeled with polynucleotide kinase at +175 , and a fragment from -13 to -487 was similarly labeled at 
-13. Approximately $4 \mathrm{ng}$ of each DNA probe was incubated with either zeste or GAGA protein and treated with DNase I in $50-\mu l$ reactions without carrier DNA, as described (Heberlein et al. 1985). Under these conditions, either $6 \mu$ l of zeste protein or $2 \mu \mathrm{l}$ of GAGA protein was sufficient to give a distinct footprint (Fig. 6).

\section{Acknowledgments}

I thank David Hogness, in whose lab this work was started. I also thank Mark Biggin and Robert Tjian for generously providing zeste and GAGA protein for footprint analysis, and I thank Barbara Graves and Suzanne Mansour for critical reading of the manuscript. This work was supported by a California Division, American Cancer Society Orway Postdoctoral Fellowship (S-55-85) and the Howard Hughes Medical Institute.

\section{References}

Akam, M. 1987. The molecular basis for metameric pattern in the Drosophila embryo. Development 101: 1-22.

Amin, J., R. Mestril, R., Lawson, H. Klapper, and R. Voellmy. 1985. The heat shock consensus sequence is not sufficient for hsp60 gene expression in Drosophila melanogaster. Mol. Cell. Biol. 5: 197-203.

Ashburner, M. 1972. Patterns of puffing activity in the salivary gland chromosomes of Drosophila. VI. Induction by ecdysone in salivary glands of $D$. melanogaster cultured in vitro. Chromosoma 38: 255-281.

Ashburner, M., C. Chihara, P. Meltzer, and G. Richards. 1974. Temporal control of puffing activity in polytene chromosomes. Cold Spring Harbor Symp. Quant. Biol. 38: 655662.

Benoist, C. and P. Chambon. 1981. In vivo sequence requirements of the SV40 early promotor region. Nature 26: 304310.

Benson, M. and V. Pirrotta. 1988. The Drosophila zeste protein binds cooperatively to sites in many gene regulatory regions: implications for transvection and gene regulation. EMBO I. 7: 3907-3915.

Benyajati, C. and J.F. Dray. 1984. Cloned Drosophila alcohol dehydrogenase genes are correctly expressed after transfection into Drosophila cells in culture. Proc. Natl. Acad. Sci. 81: 1701-1705.

Biggin, M.D. and R. Tjian. 1988. Transcription factors that activate the Ultrabithorax promoter in developmentally staged extracts. Cell 53: 699-711.

Biggin, M.D., S. Bickel, M. Benson, V. Pirrotta, and R. Tjian. 1988. zeste encodes a sequence-specific transcription factor that activates the Ultrabithorax promoter in vitro. Cell 53: 713-722.

Bond, B.J. and N. Davidson. 1986. The Drosophila melanogaster actin $5 \mathrm{C}$ gene uses two transcription initiation sites and three polyadenylation sites to express multiple mRNA species. Mol. Cell. Biol. 6: 2080-2088.

Bond-Matthews, B.J. and N. Davidson. 1988. Transcription from each of the Drosophila act5C leader exons is driven by a separate functional promoter. Gene 62: 289-300.

Breathnach, R. and P. Chambon. 1981. Organization and expression of eucaryotic split genes coding for proteins. Annu. Rev. Biochem. 50: 349-383.

Burtis, K.B. 1985. Isolation and characterization of an ecdysone-inducible gene from Drosophila melanogaster. Ph.D. thesis, Dept. of Biochemistry, Stanford University.

Corden, J., B. Wasylyk, A. Buchwalder, P. Sassone-Corsi, C. Kedinger, and P. Chambon. 1980. Promoter sequences of eu- karyotic protein-coding genes. Science 209: 1406-1414.

DiNocera, P.P. and I.B. Dawid. 1983. Transient expression of genes introduced into cultured cells of Drosophila. Proc. Natl. Acad. Sci 80: 7095-7098.

Fyrberg, E.A., J.W. Mahaffey, B.J. Bond, and N. Davidson. 1983. Transcripts of the six Drosophila actin genes accumulate in a stage- and tissue-specific manner. Cell 33: 115-123.

Gelbart, W.M. and C.T. Wu. 1982. Interactions of zeste mutations with loci exhibiting transvection effects in Drosophila melanogaster. Genetics 102: 179-189.

Goldberg, M. 1979. Ph.D. thesis, Dept. of Biochemistry, Stanford University.

Gorman, C.M., L.F. Moffat, and B.H. Howard. 1982. Recombinant genomes which express chloramphenicol acetyltransferase in mammalian cells. Mol. Cell. Biol. 2: 1044-1051.

Grosschedl, R. and M.L. Birnstiel. 1980. Identification of regulatory sequences in the prelude sequences of an $\mathrm{H} 2 \mathrm{~A}$ histone gene by the study of specific deletion mutants in vivo. Proc. Natl. Acad. Sci. 77: 1432-1436.

Gunaratne, P.H., A. Mansukhani, S.E. Lipari, H.C. Liou, D.W. Martindale, and M.L. Goldberg. 1986. Molecular cloning, germline transformation and transcriptional analysis of the zeste locus of Drosophila melanogaster. Proc. Natl. Acad. Sci. 83: 701-705.

Hatzopoulos, A.K., U. Schlokat, and P. Gruss. 1988. Enhancers and other cis-acting regulatory sequences. In Transcription and splicing (ed. B.D. Hames and D.M. Glover), pp. 43-96. IRL Press, Oxford.

Heberlein, U., B. England, and R. Tjian. 1985. Characterization of Drosophila transcription factors that activate the tandem promoters of the alcohol dehydrogenase gene. Cell 41: 965977.

Hu, S.L. and J. Manley. 1981. DNA sequence required for initiation of transcription in vitro from the major late promoter of adenovirus 2. Proc. Natl. Acad. Sci. 78: 820-824.

Hultmark, D., R.L. Klemenz, and W.J. Gehring. 1986. Translational and transcriptional control elements in the untranslated leader of the heat-shock gene hsp22. Cell 44: 429-438.

Kaufman, T.C., S.E. Tasaka, and O.T. Suzuki. 1973. The interaction of two complex loci zeste and bithorax in Drosophila melanogaster. Genetics 75: 299-321.

Kornfeld, K., R.B. Saint, P.A. Beachy, P.J. Harte, D.A. Peattie and D.S. Hogness. 1989. Structure and expression of a family of Ultrabithorax mRNAs generated by alternative splicing and polyadenylation in Drosophila. Genes Dev. 3: 243-258.

Lebowitz, P. and R.K. Ghosh. 1982. Initiation and regulation of simian virus 40 early transcription in vitro. $/$. Virol. 41: 449-461.

Luthman, H. and G. Magnusson. 1983. High efficiency polyoma DNA transfection of chloroquine treated cells. Nucleic. Acids Res. 11: 1295-1308.

Maniatis, T., E.F. Frisch, and J. Sambrook. 1982. Molecular cloning: A laboratory manual. Cold Spring Harbor Laboratory, Cold Spring Harbor, New York.

Mariani, C., B. Pirrotta, and E. Manet. 1985. Isolation and characterization of the zeste locus of Drosophila. EMBO J. 4: 2045-2052.

Mathis, D.J., and P. Chambon. 1981. The SV40 early region TATA box is required for accurate in vitro initiation of transcription. Nature 26: 310-315.

Maxam, A. and W. Gilbert. 1980. Sequencing end-labeled DNA. Methods Enzymol. 65: 499-560.

McMaster, G.K. and G.G. Carmichael. 1977. Analysis of single and double-stranded nucleic acids on polyacrylamide and agarose gels by using glyoxal and acridine orange. Proc. Natl. Acad. Sci. 74: 4835-4838. 
Nakajima, N., M. Horikoshi, and R.G. Roeder. 1988. Factors involved in specific transcription by mammalian RNA polymerase II: Purification, genetic specificity, and TATA boxpromotor interactions of TFIID. Mol. Cell. Biol. 8: 40284040.

Osborne, T.F., R.B. Gaynor, and A.J. Berk. 1982. The TATA homology and the mRNA 5 ' untranslated sequence are not required for expression of essential adenovirus E1A functions. Cell 29: 139-148.

Parker, C.S. and J. Topol. 1984. A Drosophila RNA polymerase II transcription factor contains a promoter-region-specific DNA-binding activity. Cell 36: 357-369.

Pelham, H.R.B. 1982. A regulatory upstream promoter element in the Drosophila hsp 70 heat shock gene. Cell 30: $517-528$.

Perkins, K.K., G.M. Dailey, and R. Tiian. 1988. In vitro analysis of the Antennapedia P2 promoter: Identification of a new Drosophila transcription factor. Genes Dev. 2: 1615-1626.

Pirrotta, V., E. Manet, E. Hardon, S.E. Bickel, and M. Benson. 1987. Structure and sequence of the Drosophila zeste gene. EMBO I. 6: 791-799.

Read, S.M. and D.J. Northcote. 1981. Minimization of variation in the response to different proteins of the Coomassie blue G dye-binding assay for protein. Anal. Biochem 116: 53-64.

Sanger, F., S. Nicklen, and A.R. Coulsen. 1977. DNA sequencing with chain-terminating inhibitors. Proc. Natl. Acad. Sci. 74: 5463-5467.

Sassone-Corsi, P., J.T. Dougherty, B. Wasylyk, and P. Chambon. 1984. Stimulation of in vitro transcription from heterologous promoters by the simian virus 40 enhancer. Proc. Natl. Acad. Sci. 81: 308-312.

Scott, M.P. and S.B. Carroll. 1987. The segmentation and homeotic gene network in early Drosophila development. Cell 51: $689-698$.

Sergeant, A., D. Bohmann, H. Zentgraf, H. Weiher, and W. Keller. 1984. A transcription enhancer acts in vitro over distances of hundreds of base-pairs on both circular and linear templates but not on chromatin-reconstituted DNA. I. Mol. Biol. 180: $577-600$.

Soeller, W.C., S.J. Poole, and T. Kornberg. 1988. In vitro transcription of the Drosophila engrailed gene. Genes Dev. 2: $68-81$.

Thummel, C.S., A.M. Boulet, and H.D. Lipshitz. 1988. Vectors for Drosophila P element-mediated transformation and tissue culture transfection. Gene 74: 445-456.

Topol, J., G. Wiederrecht, and C.S. Parker. 1987. Biochemical analysis of the fushi tarazu and Ultrabithorax promoter regions. In Genetic regulation of development (ed. W.F. Loomis), pp. 3-12. Alan R. Liss, New York.

Yanisch-Perron, C., J. Vieira, and J. Messing. 1985. Improved M13 phage cloning vectors and host strains: Nucleotide sequences of the M13mp18 and pUC19 vectors. Gene 33: $103-119$. 


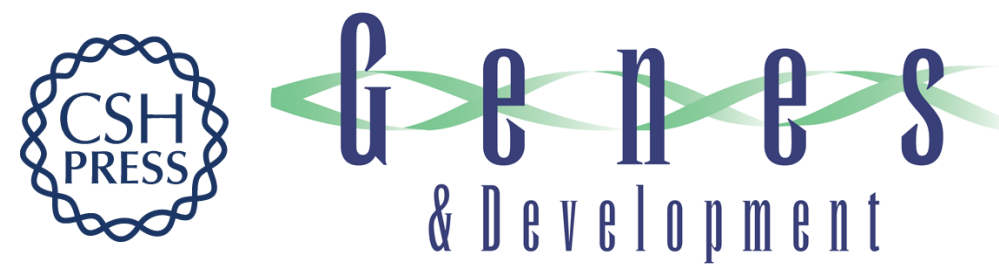

\section{The Drosophila E74 promoter contains essential sequences downstream from the start site of transcription.}

C S Thummel

Genes Dev. 1989, 3:

Access the most recent version at doi:10.1101/gad.3.6.782

References This article cites 44 articles, 21 of which can be accessed free at:

http://genesdev.cshlp.org/content/3/6/782.full.html\#ref-list-1

License

Email Alerting

Service

Receive free email alerts when new articles cite this article - sign up in the box at the top right corner of the article or click here.



